\title{
Pedestrian-level ventilation in an urban environment adjacent to a river channel: A case study for Bucharest city - Romania
}

\author{
Adrian Ciocănea ${ }^{1, *}$, Andrei Dragomirescu ${ }^{1}$, Bogdan Tofan $^{2}$ and Mihai Toti $^{3}$ \\ ${ }^{1}$ University Politehnica of Bucharest, Department of Hydraulics, Hydraulic Machinery and Environmental Engineering, \\ 313 Splaiul Independentei, 060042 Bucharest, Romania \\ 2“'Ioan Mincu" University of Architecture and Urbanism, 18-28 Academiei Str., 010014 Bucharest, Romania \\ ${ }^{3}$ National Research and Development Institute for Soil Science, Agrochemistry and Environment, 61 Marasesti Str., 11464 \\ Bucharest, Romania
}

\begin{abstract}
Increasing evapotranspiration in cities, derived from vegetation and water bodies, can effectively mitigate the effect of urban heat island (UHI). This paper presents a study on an urban ventilation solution for Bucharest City in Romania. The solution is based on lifting air volumes from the free surface of Dambovita River, which crosses the city center where UHI has a significant impact, to the roadway and pedestrian level by using cross-flow fans mounted on floating panels planted with vegetation, which are placed at the river banks. The electric motors of the cross-flow fans are powered by PV solar cells. The real optimal value of evapotranspiration (ETRO) was computed for the case of lucerne in order to assess the air temperature at the surface of the floating panel and a numerical study was performed in order to obtain the velocities of the air flow and the temperature field in a domain containing the free surface of the river, the floating panel surface, and the roadway surface (at pedestrian level). It was observed that, at low flow rates, the cooler air reaches the roadway surface in a compact jet due to the Coanda effect - the coherent air jet is of about $30-40 \mathrm{~cm}$ above the ground level. For a day with clear sky and no wind conditions a decrease in the air temperature of $4-5{ }^{\circ} \mathrm{C}$ can be obtained at the pedestrian level, within a layer of $1 \mathrm{~m}$ height. The study opens the possibility to approach such issues at a greater scale in order to assess the viability of appropriate solutions for cooling down the urban heat island as well.
\end{abstract}

\section{Introduction}

The reduced air motion at pedestrian level decreases the air quality due to the weak natural ventilation that causes pollutants to accumulate at the ground level. This negative effect is enhanced by the urban heat island (UHI) which contributes to a change in the air temperature of up to $8-10^{\circ} \mathrm{C}$ in a city center compared to rural regions. The strategies proposed to increase the outdoor air quality (OAQ) were focused on general solutions for decreasing the UHI effects, such as the minimization of heat emissions due to energy consumption [1,2] or the increase in the vegetation quantity and the albedo [3-6] using porous materials for street and pavement covers [7-10]. Under these circumstances, it results that, on the one hand, shading from trees and the evapotranspiration process are the main natural factors that contribute to the cooling effect and, on the other hand, the usage of new materials with porous characteristics, bright colors, and favorable thermal properties is the anthropic factor that must be addressed. Another category of studies established the link between UHI and pollution, which has led to research that aims to reduce the level of emissions, mostly from motor vehicles, as a solution for decreasing the temperature in large urban areas [11,12]. Recent studies are focused on modeling the wind environment at the pedestrian level and the ventilation methods $[13,14]$. This paper presents a solution for the ventilation of the pedestrian level, which uses a combined method that consists both in increasing the green area available near a river bank, to enhance the evapotranspiration process, and in lifting air volumes from the free surface of the river using cross-flow fans powered by photovoltaic solar cells. The case study is presented for Bucharest City in Romania, which is crossed by Dambovita River.

\section{Methodology}

The case study refers to a project proposed to Bucharest City Hall, which aims to reduce the effects of UHI. Bucharest is situated at a latitude of $44^{\circ} 24^{\prime} \mathrm{N}$ and a longitude of $26^{0} 05^{\prime} \mathrm{E}$. Its altitude above sea level varies between $60 \mathrm{~m}$ and $90 \mathrm{~m}$. The population density in Bucharest is of about 9,000 inhabitants per $\mathrm{km}^{2}$. By analyzing meteorological data it can be seen that UHI is most intense in the center of the city, where the soil temperature is the highest, the wind speed is the lowest, with long periods of still air (the occurrence of wind speeds below $1.5 \mathrm{~m} / \mathrm{s}$ is higher than $66 \%$ ), and the traffic-based pollution reaches maximum levels (Fig. 1).

\footnotetext{
* Corresponding author: adrian.ciocanea@upb.ro
} 
In the same time, it can be noticed that the city is crossed by the Dambovita River roughly from N-W to S-E along $22 \mathrm{~km}$.
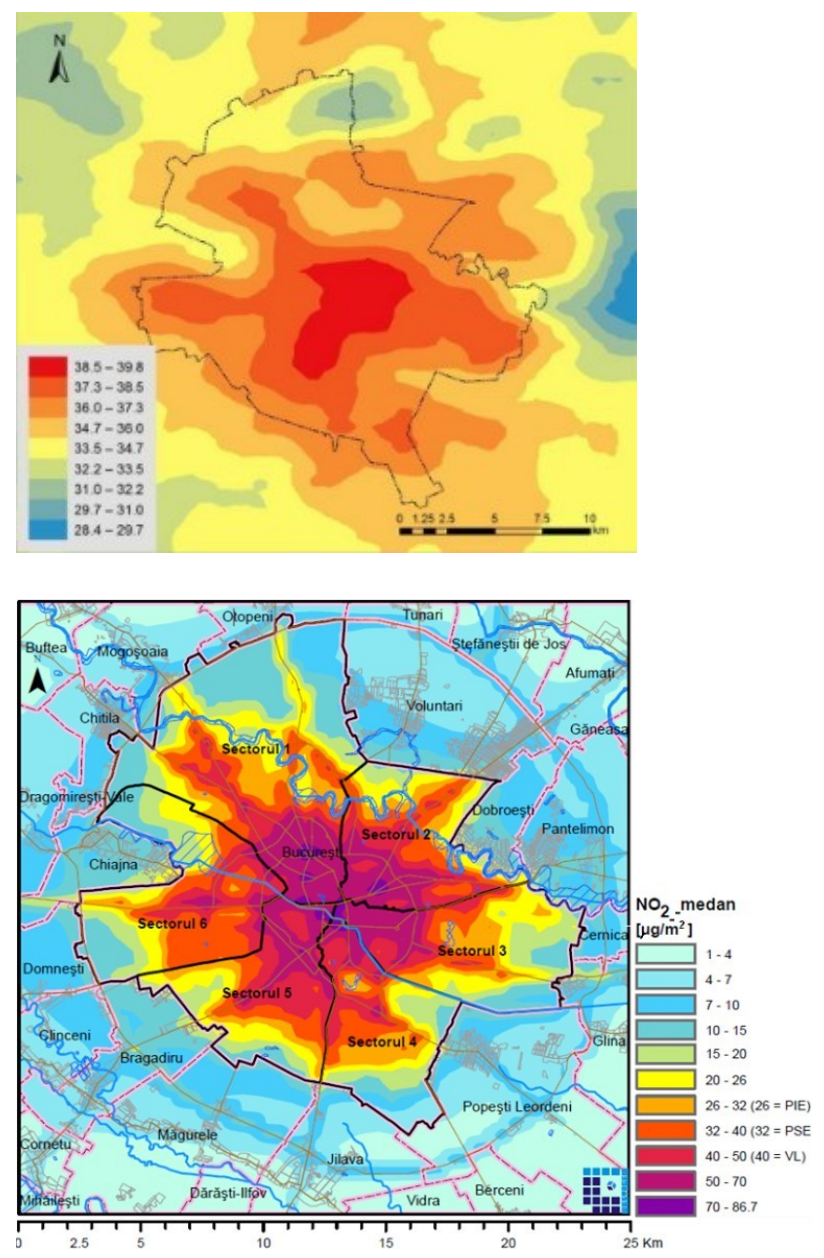

Fig. 1. Typical average temperatures of the soil $\left({ }^{\circ} \mathrm{C}\right)$ in Bucharest, in July, according to the MODIS satellite under clear sky conditions during the day (top) [15] and a map of the traffic-based pollution (bottom).

The river has a regulated flow with an average velocity that usually is of about $0.2-0.3 \mathrm{~m} / \mathrm{s}$. The concrete riverbed, forming a canal with an average width of about $30 \mathrm{~m}$ (Fig. 2), crosses the city center and has 6 canal pounds with heads of $1-2 \mathrm{~m}$ along $10 \mathrm{~km}$ in the area with high urban density. The current study was carried out in two steps. In the first step, the optimal real evapotranspiration (ETRO) for a floating panel with irrigated lucerne, denoted also as planted panel (Fig. 3), was calculated in order to assess the air temperature on the green boundary along the river. In the second step a numerical study was performed in order to obtain the velocities of the air flow and the temperature field in a domain that contains the free surface of the river, the river banks, and some part of the roadway surface (at pedestrian level). Numerical simulations were carried out for two distinct cases. The first case corresponds to the current situation, in which the river banks are made of concrete and heat up during day time due to being completely exposed to direct sunlight (Fig. 4a). The second case implements the proposed solution, in which the river banks are covered with planted panels at whose surface the temperature is expected to be significantly reduced by the evapotranspiration process (Fig. 4b).
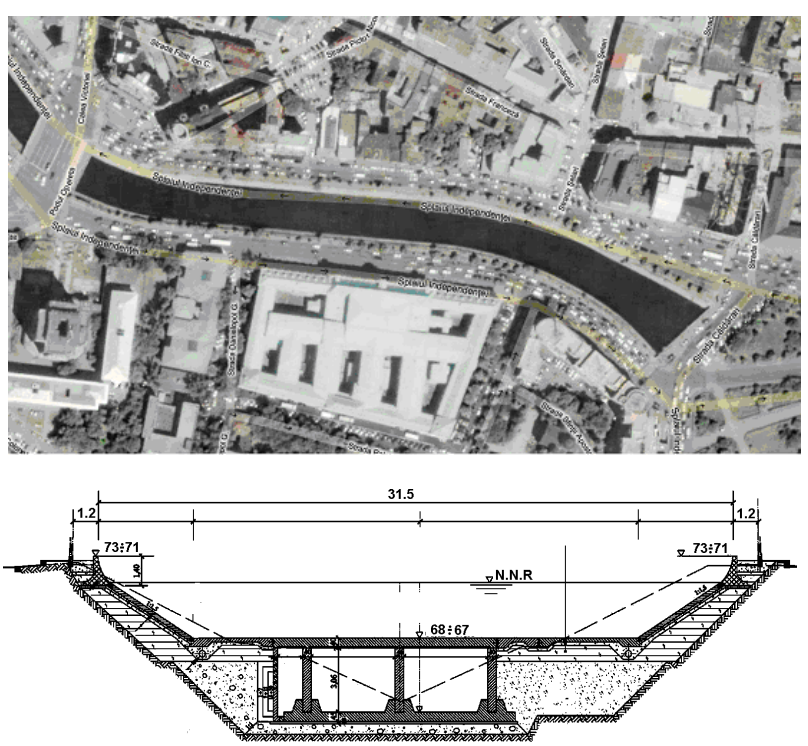

Fig. 2. River section with a length of $400 \mathrm{~m}$ considered in the study: top view (top) and canal cross-section (bottom) [16].

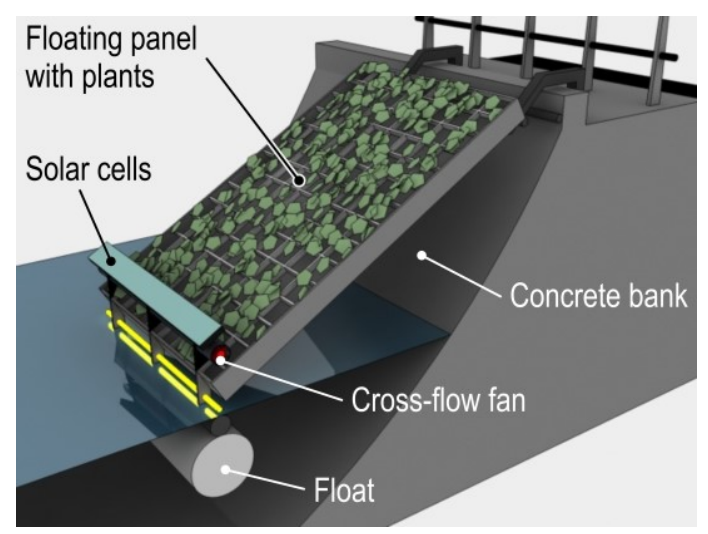

Fig. 3. Fully equipped planted panel.

\section{Theoretical model and numerical simulations}

\subsection{Calculation the value of the potential evapotranspiration}

For the current study, where the irrigation of the green area is considered, the Thornthwaite method was used. The method is based on the relationship between the water consumption of a crop and the air temperature:

$$
\mathrm{ETP}=160(10 t /)^{2} K,
$$

where ETP is the monthly potential evapotranspiration (in $\mathrm{m}^{3} / \mathrm{ha}$ ), $t$ is the multi-annual (normal) average temperature of each month for which ETP is calculated (in ${ }^{\circ} \mathrm{C}$ ), $I$ is the annual heat index of the zone where the irrigated terrain is located, being calculated as sum of the 
monthly heat indices $i, K$ is the light index corresponding to the geographical location of the studied zone, being assessed based on the average day length of each month (in hours), and $a$ is an empirical coefficient given by the following relationship:

$$
a=6.75 \times 10^{-7} I^{3}-7.71 \times 10^{-5} I^{2}+1.792 \times 10^{-2} I+0.492(2)
$$

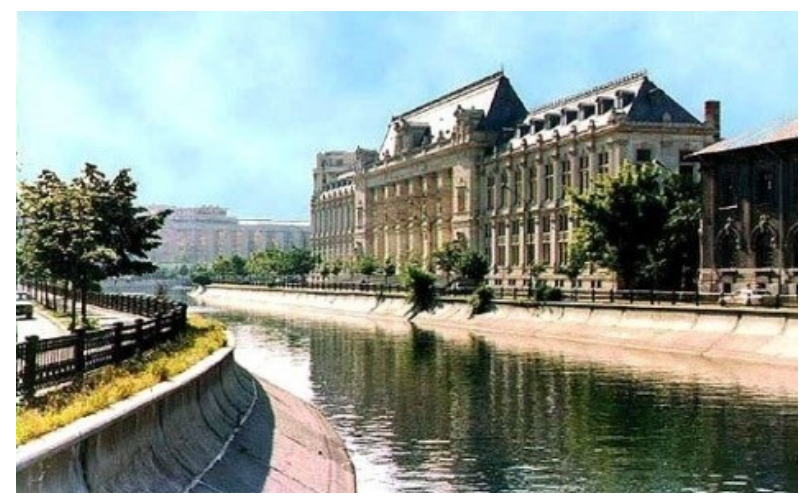

a)

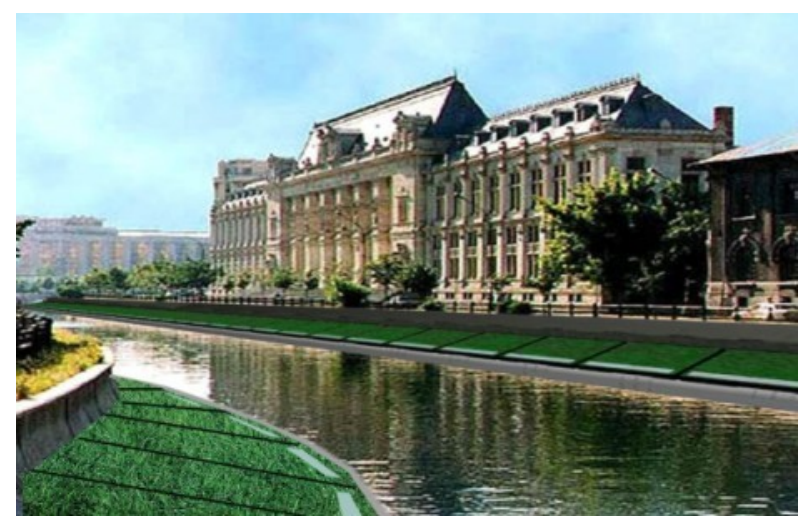

b)

Fig. 4. River banks: a) current situation and b) proposed solution.

Since the calculation of ETP is cumbersome, a simplified method was used, based on the correlation between the air temperature and the water consumption of the selected crop for monthly heat indices $i$ of 35 , 40, 45, and 50. The real optimal evapotranspiration, ETRO, represents the water consumption due to evapotranspiration of plants and to evaporation at ground surface in case of a crop supplied with the optimum quantity of water. To calculate ETRO, the following relationship is used:

$$
\mathrm{ETRO}=\operatorname{ETP} K_{p}
$$

where ETRO is the monthly water consumption of the crop (in $\mathrm{m}^{3} / \mathrm{ha}$ ) and $K_{p}$ is a correction coefficient depending on plant and growth zone. For the present study, the perennial plant chosen to be planted on the floating panels is lucerne (or alfalfa, lat. Medicago Sativa). Lucerne has high water consumption during its growing season. Between April and September, the ETP values of lucerne are the highest among the plant species cultivated in Romania. Table 1 presents values of the optimal real evapotranspiration of lucerne calculated based on the previously presented methodology and on the statistical climatic data available for the geographic zone where Bucharest is located.

Based on the data presented in Table 1, the water volume produced by evapotranspiration at the river section presented in Figure 2 and the real temperature on the upper surface of the planted panel can be assessed. For this case study, a day with clear sky in July was selected, with no wind conditions and the air temperature $T_{\text {air }}=36{ }^{\circ} \mathrm{C}(309.15 \mathrm{~K})$. Two cases were considered: $(i)$ when the panel contains only soil, without plants, and the temperature measured at the upper surface of the soil is $T_{\text {soil }}=40{ }^{\circ} \mathrm{C}(314.15 \mathrm{~K})$; (ii) when the panel contains irrigated lucerne and the temperature at the upper surface of the panel has a lower value of $T_{\text {lucerne }}=37^{\circ} \mathrm{C}(311.15$ $\mathrm{K})$. The results agree well with the study of Gkatsopoulos [17], where, for the case of a single tree placed at a window level, it was found that the external air temperature has been reduced with up to $1.5^{\circ} \mathrm{C}$.

Table 1. Optimal real evapotranspiration of irrigated lucerne under conditions typical for Bucharest.

\begin{tabular}{crrr}
\hline Month & \multicolumn{1}{c}{$\begin{array}{c}\text { ETP } \\
\left(\mathbf{m}^{3} \mathbf{h a}\right)\end{array}$} & $\boldsymbol{K}_{\boldsymbol{p}}$ & $\begin{array}{r}\text { ETRO }=\mathbf{E T P} \boldsymbol{K}_{\boldsymbol{p}} \\
\mathbf{( \mathbf { m } ^ { 3 }} \mathbf{h a} \mathbf{)}\end{array}$ \\
\hline March & 160 & 0.100 & 16.00 \\
April & 460 & 0.183 & 84.18 \\
May & 761 & 0.122 & 167.42 \\
June & 980 & 1.130 & 1107.40 \\
July & $\mathbf{1 1 1 2}$ & $\mathbf{1 . 3 8 0}$ & $\mathbf{1 5 3 4 . 5 6}$ \\
August & 1085 & 1.380 & 1492.50 \\
September & 830 & 1.430 & 1186.90 \\
October & 485 & 1.230 & 596.55 \\
\hline \multicolumn{3}{c}{ TOTAL } & $\mathbf{6 1 8 5 . 5 1}$ \\
\hline
\end{tabular}

\subsection{Numerical simulation of the air flow induced over the plants on a floating panel}

The simulation was carried out with the commercial code Ansys Fluent. At this stage, only a two-dimensional simulation was performed. It was aimed at assessing how the artificially induced air flow is influenced by the river bank geometry. Figure 5 presents the computational domain. Its boundaries are formed by a short portion of the free surface of the river, the cross-flow fan casing with the fan inlet and outlet, the upper side of the floating panel with plants, the river bank and the neighbouring sidewalk, a portion of the neighbouring road, and the contour that separates the domain from the surrounding atmosphere. The domain was meshed with an unstructured grid using quadrilateral cells. The mesh was refined at the solid boundaries (roadway, river bank and sidewalk, panel, fan casing), at fan inlet and outlet, and at the river surface, where higher velocity gradients are expected. 


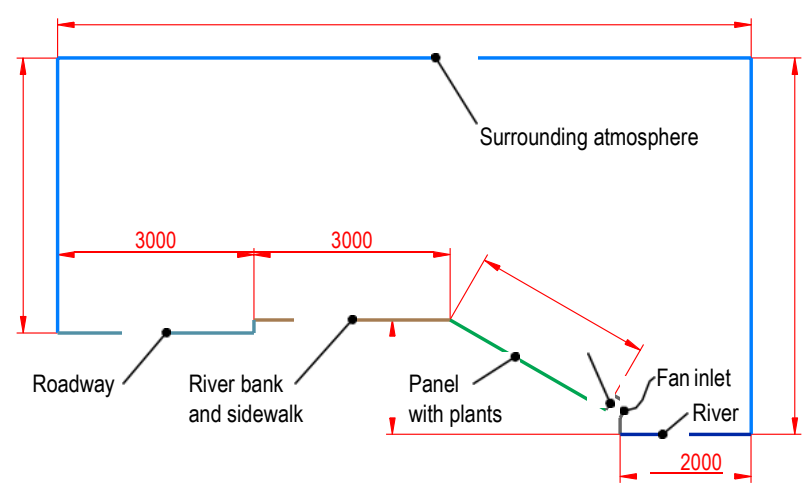

Fig. 5. Computational domain (all dimensions are in $\mathrm{mm}$ ).

The fluid is air at the reference pressure $p_{0}=10^{5} \mathrm{~Pa}$ and the reference temperature $T_{0}=36{ }^{\circ} \mathrm{C}(309.15 \mathrm{~K})$. The air flow is induced by the cross-flow fan that absorbs air close to the free surface of the river and blows an air jet over the floating panel. Since the flow are expected to be very low, the order of magnitude being of at most a few $\mathrm{m} / \mathrm{s}$, the air was considered incompressible. However, to catch the effect of possible vortices, the flow was treated as unsteady and turbulent.

The flow is governed by the continuity equation, the Reynolds averaged Navier-Stokes equations, and the energy equation. The closure for the turbulent stresses was provided by the Shear Stress Transport (SST) $k-\omega$ model, which is considered to be well suited for jet flows. At the fan outlet, an air velocity of $1 \mathrm{~m} / \mathrm{s}$ was set. The fan inlet was required to evacuate a flow rate equal to that introduced into the computational domain through the fan outlet. The no-slip condition was imposed at all solid walls.

At the boundaries that separate the domain from the surrounding atmosphere a gauge pressure of $0 \mathrm{~Pa}$ was set. The equations governing the flow were discretized in space with a second-order upwind scheme. The firstorder implicit unsteady formulation was used for the time discretization. A time step of $0.1 \mathrm{~s}$ was used. The simulation was stopped after $120 \mathrm{~s}$ of the simulation time. At each time step, the convergence criterion was the drop in all scaled residuals below $10^{-3}$, which is considered to be well suited for most of the technical problems. The numerical results of the last time step are summarized in Figure 6 in form of streamlines and velocity vectors superimposed on contours of the absolute velocity. The image is typical for the previous time steps as well since the flow pattern does not show a significant change over time. The flow obtained is similar to a large extent to a theoretical potential flow induced by a jet in the vicinity of a solid wall [18]. The jet blown by the fan has a typical structure, with a core that narrows as the jet advances on the panel (the region with a red-orange colour) and a mixing layer that grows as the jet departs from the cross-flow fan. There is only one large vortex that forms at the left boundary, above the road. The jet does not detach either at the panel surface or at the river bank and sidewalk. It only detaches at the edge of the sidewalk, but then it reattaches at the roadway. This flow pattern suggests that the Coanda effect appears and influences the jet flow, hindering its separation. The behaviour of the jet could be beneficial from the point of view of reducing the pollution level above the road. Considering the dimensions presented in Figure 5, it can be seen that the estimated height of the coherent air jet that reaches the road is of at least $30-40 \mathrm{~cm}$. This height equals the mean value of the distance between the roadway and the exhaust pipes of the motor vehicles. Thus, the additional moisture produced by evapotranspiration and entrained by the jet could help in aggregating some of the pollutant particles from above the road. Once aggregated, with their weight increased, the particles could drop and remain at ground level until washed away by street sweepers or by rain.
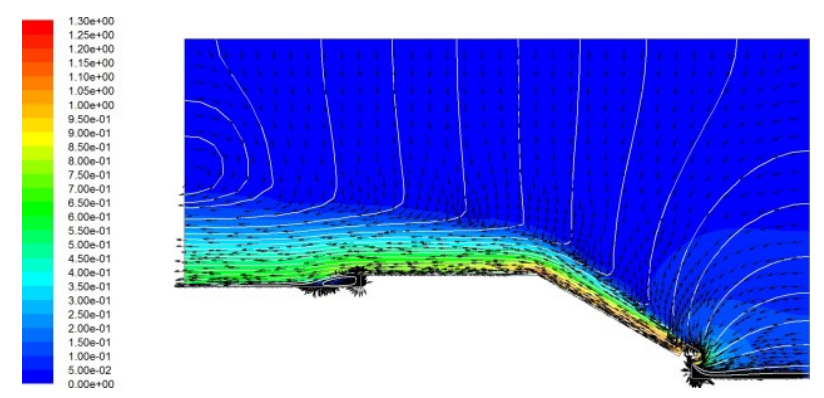

Fig. 6. Streamlines and constant length velocity vectors superimposed on contours of the absolute velocity at the last time step of the simulations.

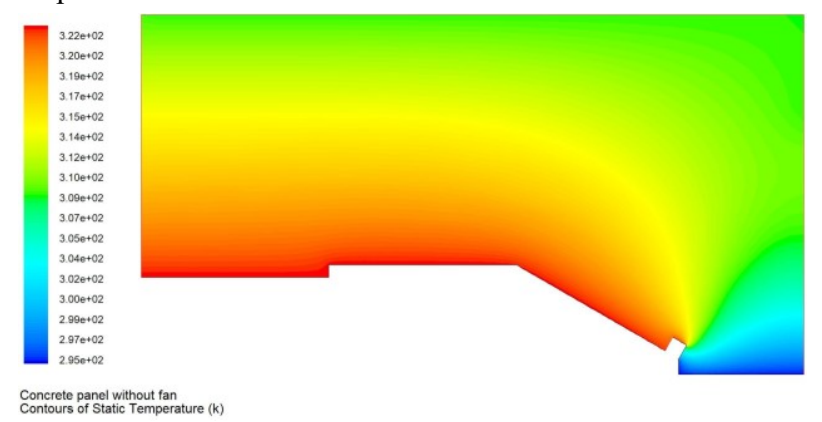

a)

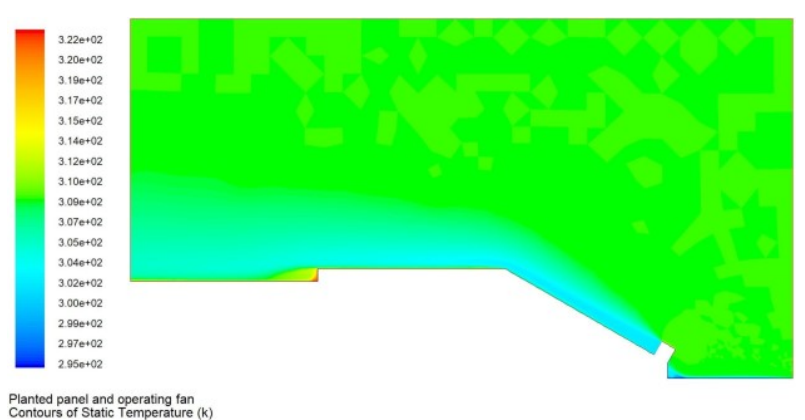

b)

Fig. 7. Variations of the air temperature: a) concrete panel without fan (case 1); b) planted panel and operating fan (case 2).

The variation of the air temperature inside the domain is presented in Figure 7 for two extreme configurations. In Figure $7 \mathrm{a}$ the reference case is 
considered (case 1), which has no forced ventilation, no wind conditions, and no planted panel. Both the river bank and the roadway are made in concrete, which, due to the solar radiation, is assumed to reach the temperature $T_{\text {concrete }}=50{ }^{\circ} \mathrm{C}(324.25 \mathrm{~K})$. In Figure $7 \mathrm{~b}$ the case of forced ventilation is considered (case 2), in which the air velocity at the cross-flow fan outlet is $v_{\text {air }}=$ $1 \mathrm{~m} / \mathrm{s}$. For this case, the panel is assumed to be planted with lucerne and the temperature of the green surface is assumed to be $\quad T_{\text {lucerne }}=37^{\circ} \mathrm{C}(311.15 \mathrm{~K})$. In both cases, the water temperature is assumed to be $T_{\text {water }}=28$ ${ }^{\circ} \mathrm{C}$.

Table 2. Comparison between the two simulation cases.

\begin{tabular}{ccccc}
\hline $\begin{array}{c}\text { Height } \\
(\mathbf{m})\end{array}$ & $\begin{array}{c}\text { Case 1 } \\
\text { Temp. 1 } \\
(\mathbf{K})\end{array}$ & $\begin{array}{c}\text { Case 2 } \\
\text { Temp. 2 } \\
(\mathbf{K})\end{array}$ & $\begin{array}{c}\text { Difference } \\
\Delta \mathrm{T}=\mathrm{T} 1-\mathrm{T} 2 \\
(\mathbf{g r d})\end{array}$ & $\begin{array}{c}\text { Air } \\
\text { velocity } \\
(\mathbf{m} / \mathbf{s})\end{array}$ \\
\hline 1 & 313 & 308.5 & 4.5 & $0.3-0.7$ \\
2 & 312 & 309.5 & 2.5 & $0.1-0.3$ \\
3 & 310 & 311 & 1 & $0.05-0.1$ \\
\hline
\end{tabular}

Considering the scale of the domain presented in Figure 5, the velocity and the temperatures at heights of 1,2 , and $3 \mathrm{~m}$ above the river bank (left hand side of the domain) can be evaluated from Figure 7 . The values obtained are presented in Table 2 for both cases: the concrete bank without fan and the planted panel with the operating fan. The data in Table 2 are in good agreement with a study of Robitu et al. [19], who showed that, in Bucharest, the cooling effect of a pond with an area of $4 \mathrm{~m}^{2}$ was of about $1{ }^{\circ} \mathrm{C}$ at a height of $1 \mathrm{~m}$, measured at a distance of $30 \mathrm{~m}$.

\section{Conclusions}

The results presented show the efficiency of the solution proposed in this paper for enhancing the pedestrian-level ventilation.

Using empirical data, the real optimal value of evapotranspiration (ETRO) and the corresponding temperature at the surface of the floating panel planted with lucerne can be calculated. Therefore, the boundary conditions of the domain can be determined: the air velocity and the temperatures at the surface of the planted panel and of the concrete river bank.Numerical simulations were performed for two extreme cases: concrete river bank without fan (case 1) and planted panel with operating fan (case 2). Both cases were considered for a day with clear sky and no wind conditions. The results show that, for the selected data, the maximum temperature difference between case 1 and 2 is of about $4.5^{\circ} \mathrm{C}$ at $1 \mathrm{~m}$ above the concrete surface. Also, due to the Coanda effect, the air jet remains coherent when flowing above the river bank. Therefore, within a layer of $1 \mathrm{~m}$ above the concrete surface, the proposed solution provides a good ventilation effect.
Even though the favourable effect diminishes in the next layer, between $1 \mathrm{~m}$ and $2 \mathrm{~m}$, a favourable temperature decrease of $2.5^{\circ} \mathrm{C}$ could still be obtained. Further studies will focus on the influence of the relative air humidity on the temperature variation.

\section{References}

1. M. Santamouris, N. Papanikolau, I. Livada, Koronakis, C. Georgakis, A. Argiriou, D.N. Assimakopoulos, Solar Energy 70, 201 (2001)

2. M. Santamouris, A. Synnefa, T. Karlessi, SolarEnergy 85, 3085 (2011)

3. H. Akbari, M. Pomerantz, H. Taha, Solar Energy 70, 295 (2001)

4. M.F. Shahidian, J.P. Jones, J. Gwilliam, E. Salleh, Building and Environment 58, 245 (2012)

5. L. Shashua-Bar, M.E. Hoffman, Energy and Buildings 31, 221 (2000)

6. W.D. Solecki, C. Rosenzweig, L. Parshall, G. Pope, M. Clark, J. Cox, M. Wiencke, Environmental Hazards 6, 39 (2005)

7. M. Bruse, Envi-met v3.1, a microclimate urban scale model, Online (2009), http://www.envi-met.com

8. A. Dimoudi, S. Zoras, A. Kantzioura, X. Stogiannou, P. Kosmopoulos, C. Pallas, Sustainable Cities and Society 13, 89 (2014)

9. P. Putrajaya, Putrajaya Annual Report 2008 (2008)

10. M. Santamouris, D.N. Asimakopulos, V.D. Asimakopulos, N. Chrisomallidou, N. Klitsikas,

P. Michel, M. Santamouris, A. Tsangrassoulis, Energy and climate in the urban built envir. (James \& James (Science Publishers) Ltd., London, (2001)

11. P.A. Mirzaei, F. Haghighat, Journal of Wind Engineering and Industrial Aerodynamics 99, 46 (2011)

12. A. Wania, M. Bruse, N. Blond, C. Weber, Journal of Environmental Management 94, 91 (2012)

13. Y. Du, C.M. Mak, Z. Ai, Environmental Modelling \& Software 103, 105 (2018)

14.P.A. Mirzaei, F. Haghighat, Building and Environment 45, 1582 (2010)

15. S. Cheval, A. Dumitrescu, Theoretical and Applied Climatology 121, 631 (2014)

16. D. Stematiu, D. Teodorescu, Dambovita River in Bucharest - the defense system against floods, in Proc. 7th Ed. Annual Conf. of ASTR, (in Romanian) (Bucharest, Romania, 2012)

17. P. Gkatsopoulos, Procedia Environmental Sciences 38, 477 (2017)

18. H. Schlichting, K. Gersten, Boundary Layer Theory (Springer, Berlin, 2000) 
19. M. Robitu, C. Inard, D. Groleau, M. Musy, Building Services Engineering Research and Technology 25, 171 (2004) 